\title{
The Mechanism and Control Technology of Strong Strata Behavior in Extra-Thick Coal Seam Mining Influenced by Overlying Coal Pillar
}

https://doi.org/10.1515/geo-2019-0036

Received Oct 02, 2018; accepted Jan 08, 2019

\begin{abstract}
This work aimed at revealing the mechanism of strong strata behavior in extra-thick coal seam mining which was influenced by an overlying coal pillar (OCP). To this end, the evolution characteristics of the stress and displacement in advance coal body of the working face were studied via numerical simulation. On this basis, the mechanism of strong strata behavior in working face affected by OCP was revealed. In situ monitoring also demonstrated that, as the working face mining near to the position of OCP, severe rib spalling and roadway deformation frequently appeared. The scheme of strengthening the hydraulic supports resistance and adding anchor cables was put forward to control the surrounding rocks in the stope. As a result, the maximum deformation of the roadway height was $0.66 \mathrm{~m}$ and could completely meet the demands for safe mining. The study on the mechanism of strong strata behavior in working face and the strengthen supporting scheme would provide a theoretical basis for similar mining conditions, thus ensure safe and efficiency coal seam mining.
\end{abstract}

Keywords: strong strata behavior, overlying coal pillar (OCP), extra-thick coal seam, control technology

\footnotetext{
${ }^{\star}$ Corresponding Author: Rui Gao: College of Mining Engineering, Taiyuan University of Technology, Shanxi 030024, China; Email: cumtgaorui@163.com; Tel.: 13813464961

*Corresponding Author: Tiejun Kuang: Datong Coal Mine Group Co. Ltd. , Datong 037000, China; Key Laboratory of Deep Coal Resource Mining, School of Mines, Ministry of Education of China, China University of Mining and Technology, Xuzhou, 221116, China; Email: kuangtiejun@163.com Yiwen Lan: Datong Coal Mine Group Co. Ltd., Datong 037000, China; Key Laboratory of Deep Coal Resource Mining, School of Mines, Ministry of Education of China, China University of Mining and Technology, Xuzhou, 221116, China; Email: db15020012b4cx@cumt.edu.cn
}

\section{Introduction}

In China, the coal is the primary energy resource. Thick and extra-thick coal seams are the principal coal seams of importance due to their high production and efficiency. With a high yields and efficient extraction, the production of extremely thick coal seams account for $50 \%$ of energies. The thick and extremely thick coal seams are mainly distributed in the Shanxi, Shaanxi, Inner Mongolia, and Xinjiang regions of China, and the total reserves amount to over a trillion tons.

During the mining of thick and extremely thick coal seams, the strata behavior occurred in the working faces are generally intense due to the large coalface spaces and wide movement range in overlying rocks. Especially, when the coal seam buried deeply, the stress concentration in coal body is obvious, and the breakage of overlying strata are complex, thus result in a strong strata behavior in working face and roadway. For example, the mining of an extrathick in the Datong mining area of China (20m thickness, $500 \mathrm{~m}$ depth), frequently lead to the crushed of supports which with a resistance of $15,000 \mathrm{kN}$, also accompanied by severe deformation in the roadways [1-3]. Several research groups have carried out a great deal of researches on the forecast and control of ground pressure in coal seam mining [4-9]. Chen et al. [4] studied the mechanism of rock burst induced by the occurrence of layer-crack plate structure in the coal wall during a deep coal seam mining. Some researchers [5-9] focused on the failure and movement of overlying strata induced by underground mining.

Meanwhile, the method of liberated-seam mining is regarded as an effective way to control the strong strata behavior, as it could damage the integrity of overlying strata in advance, thus reduce the stress accumulation during underlying coal seam mining [10].

When liberated-seams are affected by the mining environment during mining process, coal pillars are retained. Due to the stress concentration in retained coal pillars, strong strata behavior would appear when underneath extremely thick coal seams mining. However, most of the

ə Open Access. (c) 2019 R. Gao et al., published by De Gruyter. (CC) BY License 


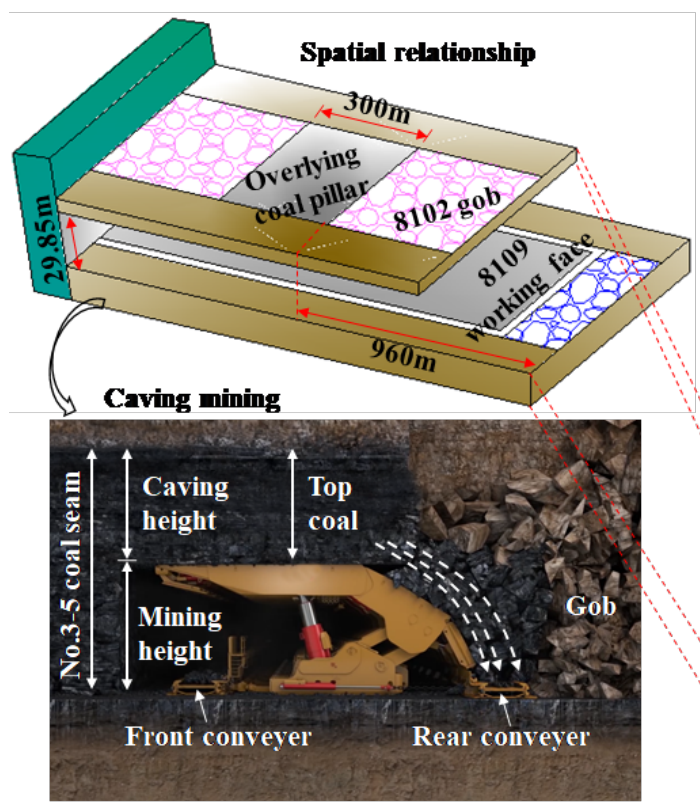

Lithology and parameters of overlying rock

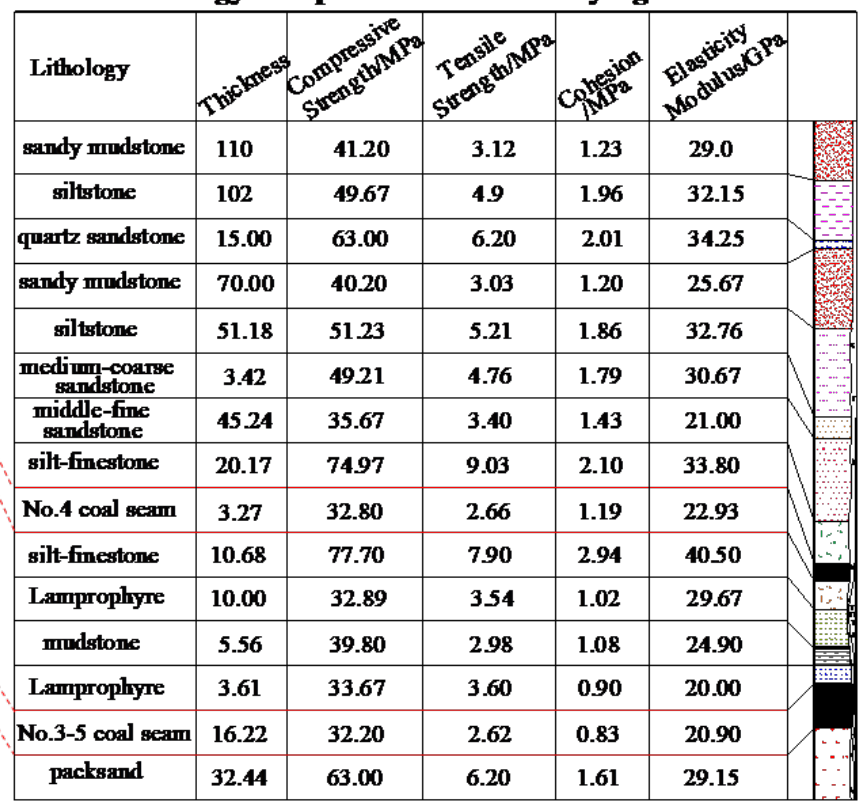

Figure 1: Spatial relationship of the working faces and the OCP.

traditional researches focused on the stress concentration on OCP, e.g. Poulsen et al. [11] and Singh et al. [12-14] focused on the coal pillar loads by calculating and estimating, Jaiswal et al. [15] and Mohan et al. [16] investigated the pillar strength using numerical method, Wattimena et al. [17] evaluated coal pillar stability by logistic regression. Other scholars have conducted researches that are relevant as well $[18,19]$. When it comes to the ground pressure in the coal seam influenced by the OCP, only fewer studies have been carried out, e.g. Ju Jinfeng et al. [20, 21] explored the crushing mechanism acting on supports during the working face passed close to coal pillars in shallow coal seams. Yang Jingxuan et al. [22, 23] studied the stress transfer characteristics from OCP loads using theoretical analysis. Xia Binwei et al. [24] studied the strong strata behavior under the coupling effects of hard roof fracturing and OCP occurrence.

However, due to the movement of the overlying rocks during the mining process, the stress distributed in OCP changes dynamically. Therefore, the stress field around the working face influenced by OCP changes constantly. However, in Ju's study [20, 21], the instability mechanism of strata underneath the OCP and the following phenomenon of supports crushed was analyzed completely. Nonetheless, the stress distributed in OCP and coal body in front of the working face were absented. As to Yang's study [22, 23], only the transfer characteristics of stress distributed in coal pillars was given, so it's necessary to study the dynamic stress distribution around the OCP and work- ing face, thus to give the mechanism of strong strata behavior in working face. In the paper, the characteristics of the stress distribution around the working face under dynamic loads from the OCP was analyzed by numerical simulation and theoretical. Finally, certain methods were used to control strong strata behavior in order to ensure safe production.

\section{Engineering Background}

The Datong mining area, which was formed by double system formation, has been gradually mined to its deep parts. The deeper coal seams are mainly reserved in the Shanxi formation of Permian system and Taiyuan formation of Carboniferous system which include Shanxi No.4, 2, 3-5, and 8 coal seams. The No.3-5 extra-thick coal seam of Carboniferous system is mainly mined in Tashan coal mine. The burial depth and thickness of No.3-5 coal seam are $400 \mathrm{~m}$ to $600 \mathrm{~m}, 15 \mathrm{~m}$ to $20 \mathrm{~m}$, respectively. The No.3-5 coal seam was mined by the method of caving mining, as the mining height was $3 \mathrm{~m}$ to $5 \mathrm{~m}$ and caving height was $10 \mathrm{~m}$ to $17 \mathrm{~m}$. The lithology and parameters of all the overlying rock are shown in Figure 1. As the mining height of No.3-5 coal seam is huge, the strata behavior is intense and strong, the supports crushed and severe deformation in roadways occurred frequently [3-5]. 


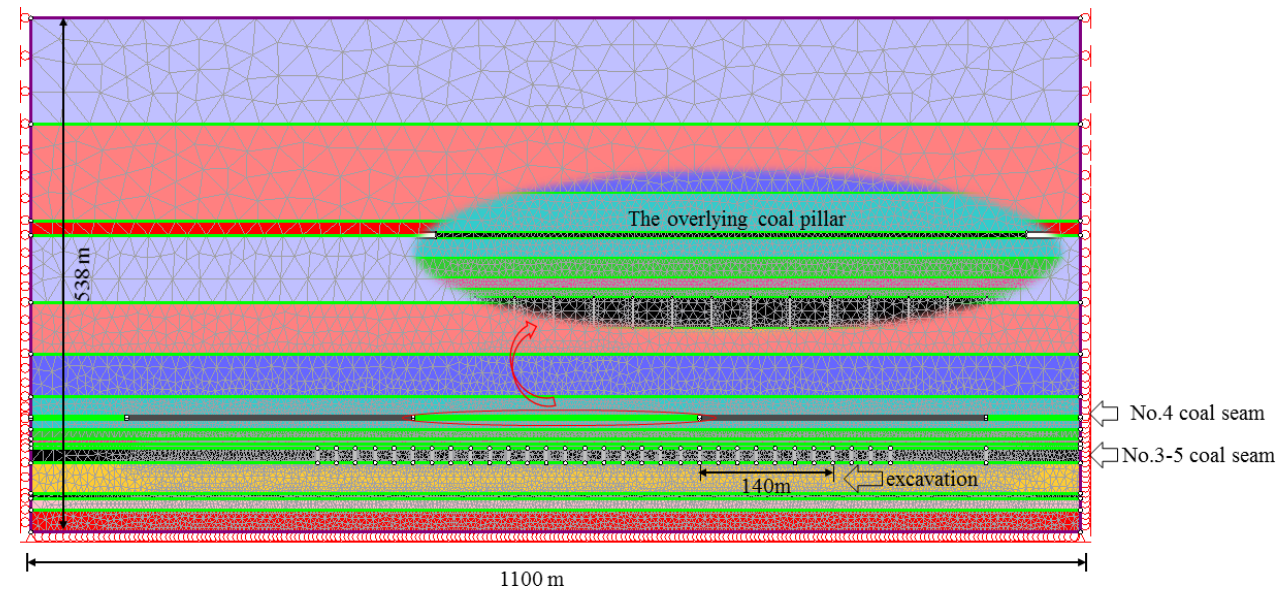

Figure 2: The numerical simulation model.

In order to reduce the magnitude of the strata behavior during No.3-5 coal seams mining, the overlying Shanxi No.4 coal seam was mined firstly. The overlying 8102 working face which was mining the Shanxi No.4 coal seam, the mining thickness and length of 8102 working face were $3.27 \mathrm{~m}$ and $228 \mathrm{~m}$, respectively. During the mining of the 8102 working face, a $300 \mathrm{~m}$ section along the mining direction was not excavated due to an intrusion of igneous rock. The vertical distance between the No.3-5 and Shanxi No.4 coal seams is $23 \mathrm{~m}$ to $35 \mathrm{~m}$ ( $29.85 \mathrm{~m}$ on average). The length, average mining thickness, and burial depth of the 8109 working face were $207 \mathrm{~m}, 16.22 \mathrm{~m}$, and $467.38 \mathrm{~m}$, respectively and the No.3-5 coal seam was nearly horizontal. The lithology between No.4 coal seam and No.3-5 coal seam were consist of silt-finestone, lamprophyre and mudstone. The $300 \mathrm{~m}$ long OCP retained in the 8102 working face corresponding to the position of $960 \mathrm{~m}$ to $1260 \mathrm{~m}$ from the open-off cut of the 8109 working face (Figure 1).

\section{Numerical Simulation}

As the 8109 working face gradually mined near to the position of OCP, caving occurred in the overlying strata, and the stress distributed in the OCP changed correspondingly. This resulted in the dynamically changing of stress and displacement in the advanced coal body of 8109 working face.

\subsection{The Simulation Model}

A model was established based on the Mohr-Coulomb yield criterion in which the coal-rock masses were regarded as elastic-plastic materials using a software of
Phase-2D. Phase-2D could been widely used in stressdisplacement calculation in the scope of rock-soil and engineering. The size of the model and the length of mining distance were taken as $1100 \times 538 \mathrm{~m}$ and $140 \mathrm{~m}$, respectively. The lateral boundaries were fixed in displacement at the horizontal direction, the bottom boundary was fixed in displacement at the horizontal and vertical direction, and the top boundary was set free. The buried depth of No.3-5 coal seam is $467 \mathrm{~m}$, no load was loaded at the top of model and gravitational stress was used in the model. As the lateral boundaries were fixed, the horizontal stress of the model was automatically calculated by Phase-2D. The in-situ stress of No.3-5 coal seam is $11.67 \mathrm{MPa}$. The physical and mechanical parameters of each coal-rock layer in the model are shown in Figure 1.

The distribution laws of the stress and displacement in advanced coal body of the working face, as well as the stress in the OCP, were recorded for every $20 \mathrm{~m}$ during the working face mining, and the recording started when the 8109 working face was $140 \mathrm{~m}$ away from the OCP (Figure 2).

\subsection{Analysis of Results}

\subsubsection{Abutment stress distribution in front of working face}

The distribution of the abutment stress in front of the 8109 working face were gained when the working face gradually mined to positions of $140,100,60,20$, and 0 m horizontally from the OCP , as shown in Figure 3.

When the 8109 working face was $140 \mathrm{~m}$ away from the OCP, the stress in advance coal body increased firstly and then decreased (Figure 3a). Due to the concentrated 

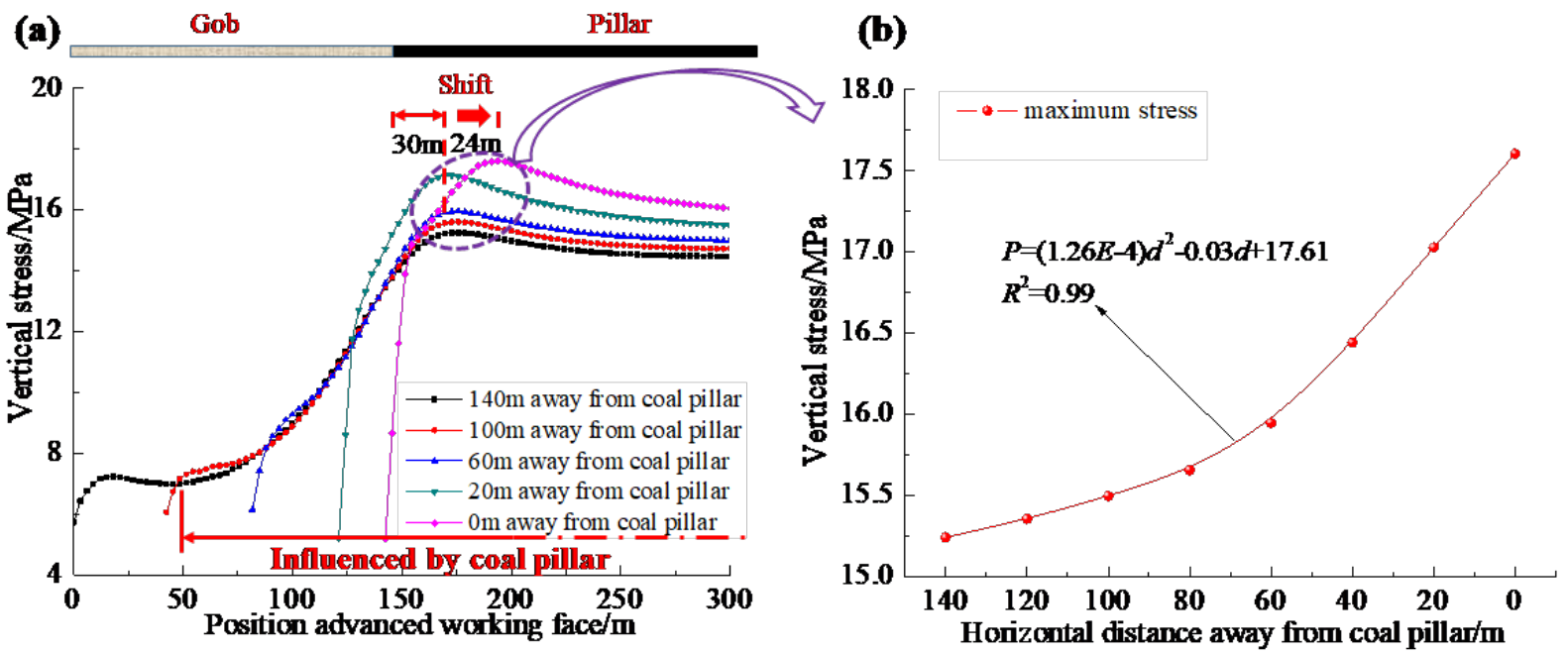

Figure 3: Characteristics of the stress of the coal body in front of the working face: (a) Distribution of the stress in the coal walls; (b) Plot of the maximum stress occurring.

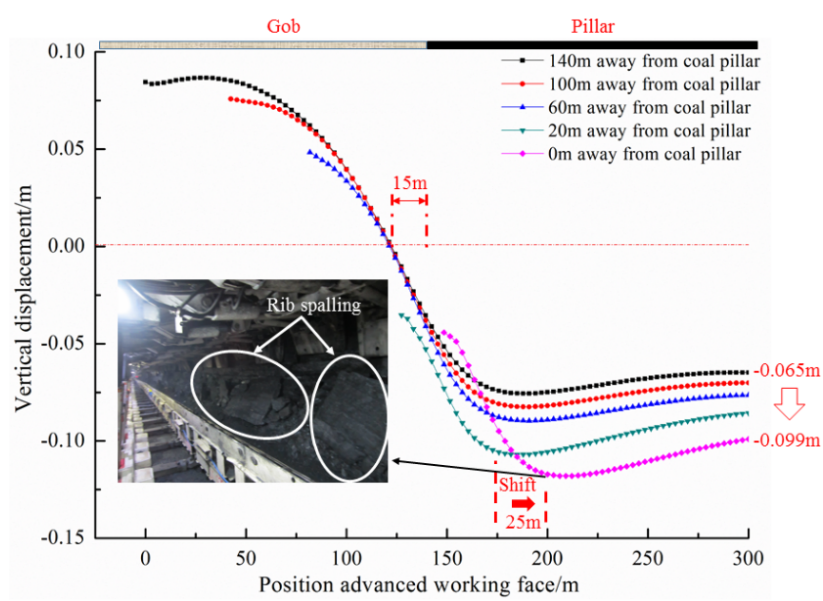

Figure 4: Vertical displacement of the advanced coal body.

stress in the OCP, the stress curve rose again at $50 \mathrm{~m}$ point which indicated that the influence range of the concentrated stress in the OCP was $90 \mathrm{~m}$. During the distance between the working face and OCP was within $100 \mathrm{~m}$, the stress in the advanced coal body increased continuously, and then stabilized after reaching a maximum value at the point $30 \mathrm{~m}$ inside the boundary of the OCP.

When 8109 working face was beneath the OCP $(0 \mathrm{~m}$ from the OCP), Figure 3 a shows that the position of the peak value in the advanced stress curve shifted by $24 \mathrm{~m}$ compared to the former four curves. This is because that the OCP was damaged in the edges and the bearing stress in the edge of the OCP significantly decreased and transferred to the deeper parts of the OCP, resulting in a shift of the peak in the advanced stress.
As the working face gradually mined to the position of OCP, the peak value of the abutment stress in advanced coal body was increased. Therefore, the change of peak value as the working face advanced from 140 to $0 \mathrm{~m}$ away from the OCP was explored (Figure 3b). The peak value in front of the working face increased in a parabolic manner as the working face advancing (Figure $3 \mathrm{~b}$ ). It rose gently when working face was $80 \mathrm{~m}$ to $140 \mathrm{~m}$ from the OCP, and then became more rapidly as the working face was advanced beyond the $80 \mathrm{~m}$ point (the advanced stress was greatly affected by the OCP here and the peak value rapidly increased from 15.65 to $17.6 \mathrm{MPa}$ ). Clearly, the closer the working face was to the OCP, the more seriously the surrounding rocks of the coalface were affected by the concentrated stress in the OCP. Therefore, stricter requirements were called to control the surrounding rocks of the coalface.

\subsubsection{Displacement in front of the working face}

The variation of the vertical displacement in advanced coal body was obtained when the 8109 working face was 140 , $100,60,20$, and $0 \mathrm{~m}$ away from the OCP, as shown in Figure 4.

In Figure 4, a positive value (+) on the vertical coordinate represents the situation wherein the coal body were displaced upwards (i.e. opposite to the direction of gravity) under a squeezing action, while a negative value (-) indicates downwards displacement (along the direction of gravity) under a compressive action. 


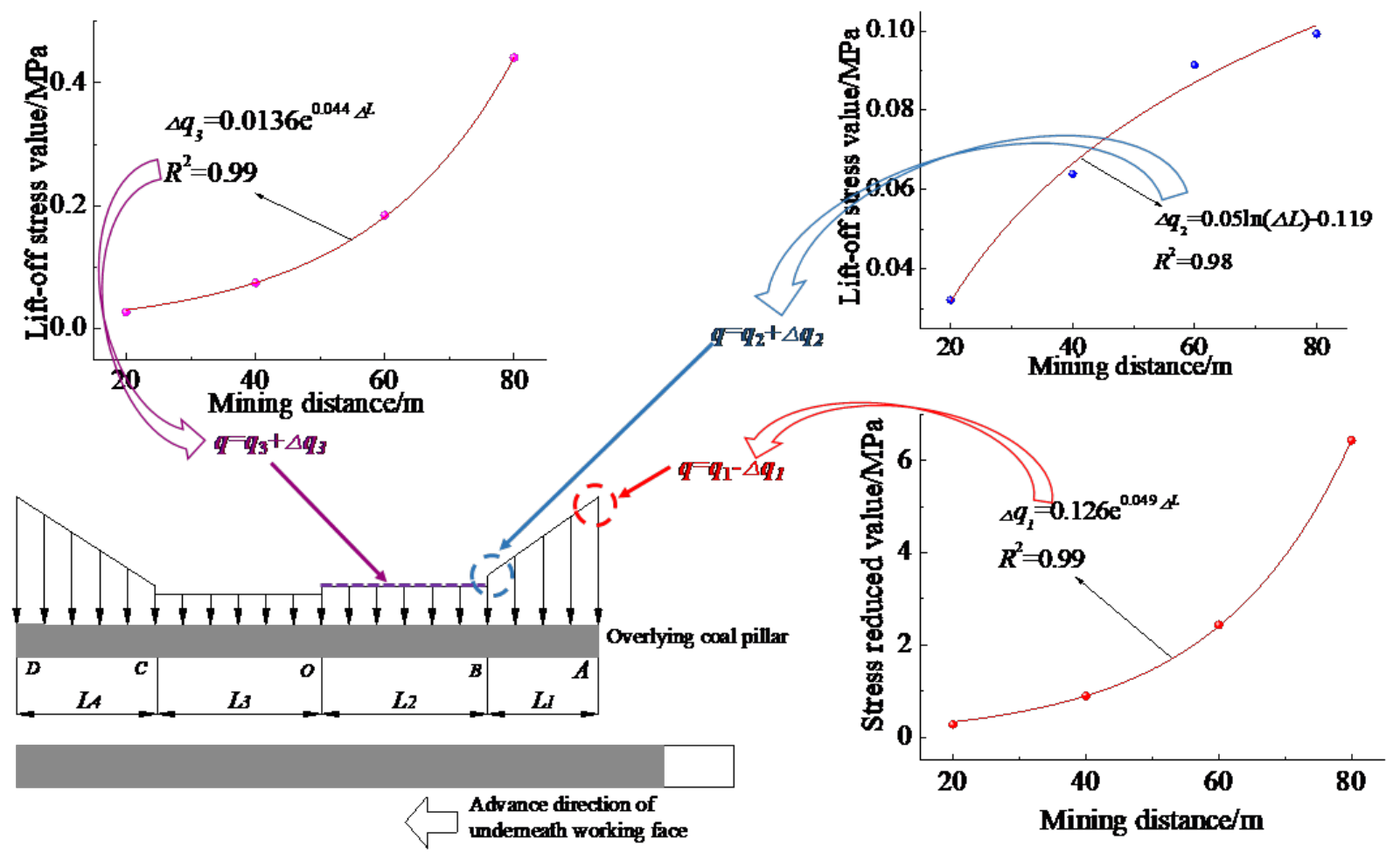

Figure 5: Dynamic changes of the stress in the coal pillar.

When the 8109 working face was 140,100 , and $60 \mathrm{~m}$ from the OCP, the vertical displacements were first in the '+' zone and then in the '-' zone. This is because the overlying coal seam was mined and the stress was unloaded in advance, causing the coal seams underneath the overlying goaf to be unloaded and displaced along the opposite direction of gravity under the extrusion and disturbance of the mining stress during No.3-5 coal seam mining. Furthermore, as the working face gradually mined to the position underneath the OCP, the coal body was strongly compressed and gradually the displacement changed to be in the direction of gravity at point $15 \mathrm{~m}$ from the OCP.

When the 8109 working face was within $20 \mathrm{~m}$ from the OCP, the displacements in advanced coal body obviously correspond to compression ('-') and the vertical displacement of the coal body increased constantly and then stabilized. As demonstrated in Figure 4, when the working face advanced beneath the OCP, the peak displacement of the coal body moved $25 \mathrm{~m}$ to the deeper part of the OCP. This is an indication that the OCP was broken and the overlying stress was being transferred to the deeper parts of the OCP.

It can be seen from Figure 4 that as the working face mined near to the OCP, the stabilized displacement in advanced coal body increased continuously from $0.065 \mathrm{~m}$ to $0.099 \mathrm{~m}$. Moreover, the working face was compressed more markedly, mainly manifested in the form of rib spalling and roadway severely deformed.

\section{Theoretical Analysis}

In order to investigate the stress dynamic changing in the OCP with the mining of the working face and to express it clearly according to the numerical simulation data, the overlying coal pillar was divided into four sections: L1, L2, L3, and L4. Of these, section L1 correspond to $0 \mathrm{~m}$ to $43 \mathrm{~m}$ in the mining direction, section L2 correspond to $43 \mathrm{~m}$ to $159 \mathrm{~m}$, sections L3 and L4 correspond to $159 \mathrm{~m}$ and $300 \mathrm{~m}$. The dynamic changing of stress in sections L1 and L2 are shown in Figure 5.

In section $\mathrm{L}_{1}$ (Segment I), the stress was distributed approximately trapezoidal. Two key points A and B (corresponding to $x=0$ and $x=43$ in section L1) on the oblique line segments was further analyzed. The initial stress values at points $\mathrm{A}$ and $\mathrm{B}$ were defined as $q_{1}$ and $q_{2}$ when the working face was $100 \mathrm{~m}$ away from the OCP, respectively. The change in stress with the mining interval of the working face, $\Delta \mathrm{L}$, at these two points were found to obey $\Delta q_{1}=0.126 \mathrm{e}^{0.049 \Delta \mathrm{L}}$ and $\Delta q_{2}=0.05 \ln (\Delta \mathrm{L})-0.119$, respectively. Thus, the stress changing at points $\mathrm{A}$ and $\mathrm{B}$ 


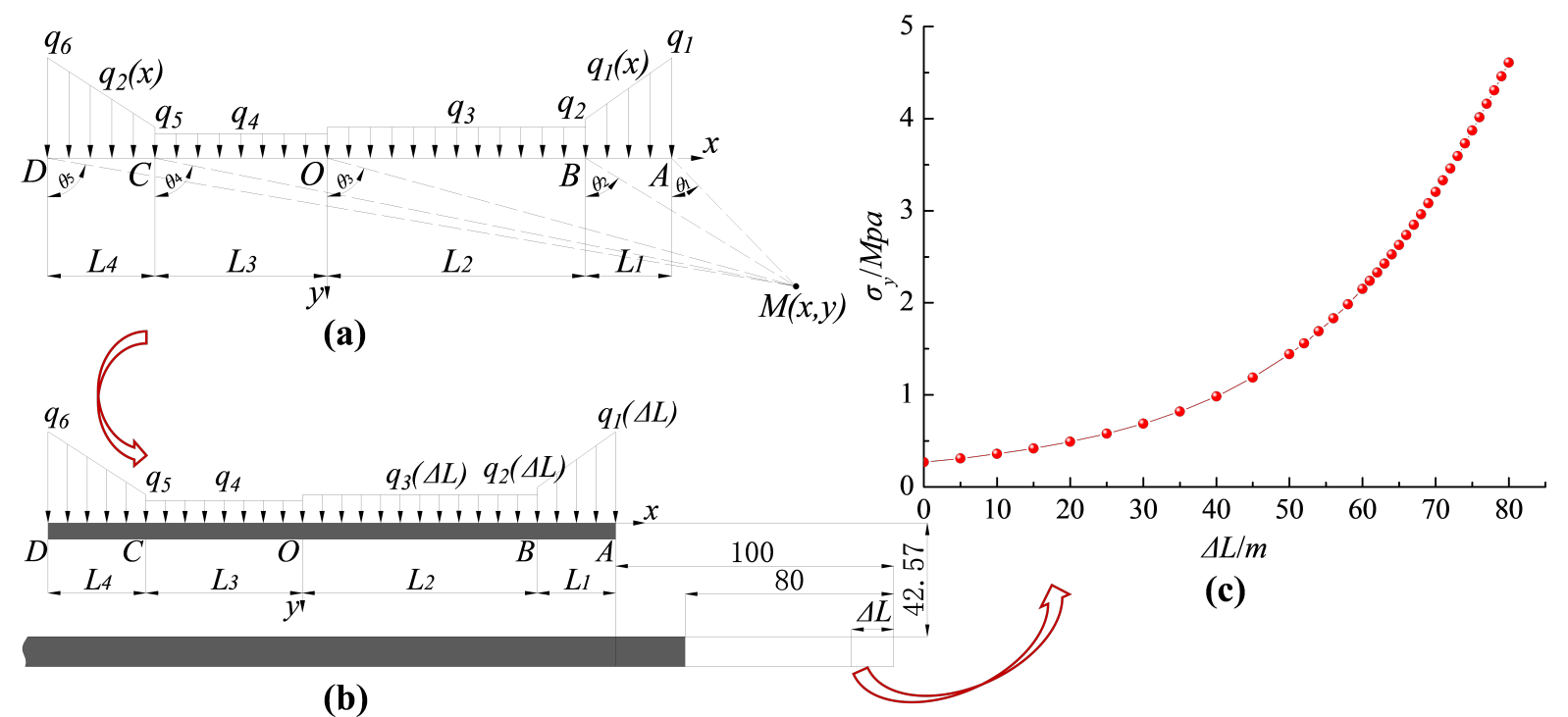

Figure 6: Calculating schemes of vertical stress in the working face affected by OCP:(a) Model for calculating the stress below the OCP ; (b) Relative locations of the OCP and 3-5\# coal seam ; (c) Relationship between $\sigma_{y}$ and $\Delta \mathrm{L}$.

with the mining interval of the working face were $q_{A}=$ $q_{1}-0.126 \mathrm{e}^{0.049 \Delta \mathrm{L}}$ and $q_{B}=q_{2}+0.05 \ln (\Delta \mathrm{L})-0.119$, respectively.

In section $\mathrm{L}_{2}$ (Segment II), the loads can be approximately regarded as uniformly distributed and the average loads value was used for the stress value in this section. Similarly, as the working face mining, the uniformly distributed loads value also varied. By taking the position wherein the working face was $100 \mathrm{~m}$ from the OCP as a base data, and marked the uniformly distributed loads value as $q_{3}$, the changing in stress with $\Delta \mathrm{L}$ was found to be $\Delta q_{3}=0.0136 \mathrm{e}^{0.044 \mathrm{~L}}$. Therefore, the uniformly distributed loads in $\mathrm{L}_{2}$ varied in the form $q=q_{3}+0.0136^{\mathrm{e} 0.044 \Delta \mathrm{L}}$.

Based on the numerical simulations, the loads changed in $\mathrm{L}_{3}$ and $\mathrm{L}_{4}$ of the OCP (Segment III) can be approximately considered as insignificant and were taken to be a constant value.

In order to calculate the stress at a point $\mathrm{M}(\mathrm{x}, \mathrm{y})$ below the OCP, a model was established (Figure 6a). According to the elastic mechanics theory, the vertical stress $\sigma_{y}$ at any point $M$ in the bottom plate was component of the vertical stress resulting from the loads of sections $\mathrm{AB}, \mathrm{BO}, \mathrm{OC}$, and $\mathrm{CD}$, as shown in equation (1), and after calculation, the expression of $\sigma_{y}$ was found to be as equation (2).

$$
\sigma_{y}=\sigma_{y 1}+\sigma_{y 2}+\sigma_{y 3}+\sigma_{y 4}
$$

$$
\begin{gathered}
\sigma_{y}=\frac{1}{\pi}\left[\begin{array}{c}
-\frac{y\left(x-L_{2}-L_{1}\right) q_{1}}{y^{2}+\left(x-L_{2}-L_{1}\right)^{2}}+\frac{\left(q_{2}-q_{3}\right) y\left(x-L_{2}\right)}{y^{2}+\left(x-L_{2}\right)^{2}} \\
+\frac{\left(q_{3}-q_{4}\right) x y}{y^{2}+x^{2}}+\frac{\left(\frac{\left(x_{4}-q_{5}\right) y\left(x+L_{3}\right)}{y^{2}+\left(x+L_{3}\right)^{2}}\right.}{\left.+\frac{y\left(x+L_{3}+L_{4}\right) q_{6}}{y^{2}+\left(x+L_{3}+L_{4}\right)^{2}}-q_{2} \arctan \frac{x-L_{2}-L_{1}}{y}\right)} \\
+\left(q_{2}-q_{3}\right) \arctan \frac{x-L_{2}}{y}+\left(q_{3}-q_{4}\right) \arctan \frac{x}{y} \\
+\left(q_{4}-q_{5}\right) \arctan \frac{x+L_{3}}{y}+q_{5} \arctan \frac{x+L_{3}+L_{4}}{y}
\end{array}\right] \\
+\frac{\left(q_{1}-q_{2}\right)\left(x-L_{2}\right)\left(\arctan \frac{x-L_{2}}{y}-\arctan \frac{x-L_{2}-L_{1}}{y}\right)}{\pi L_{1}} \\
-\frac{\left(q_{6}-q_{5}\right)\left(x+L_{3}\right)\left(\arctan \frac{x+L_{3}+L_{4}}{y}-\arctan \frac{x+L_{3}}{y}\right)}{\pi L_{4}}
\end{gathered}
$$

For $q_{1-6}$ and $\mathrm{L}_{1-4}$ in Eq. (2), according to the numerical simulations, we knew that $q_{1-3}$ were functions of the mining interval $\Delta \mathrm{L}$, while the value of $q_{4-6}$ change only slightly and can therefore be regarded as constants. Moreover, the values of $\mathrm{L}_{1-4}$ can be obtained from the simulation results. Regarding the data when the working face was $100 \mathrm{~m}$ horizontally away from the OCP as a benchmark (that is, the initial values were $q_{1}=29.936 \mathrm{MPa}, q_{2}=15.028 \mathrm{MPa}$, and $q_{3}=14.222 \mathrm{MPa}$ ), the expressions for each loads as a function of $\Delta \mathrm{L}$ are:

$$
\begin{aligned}
& q_{1}(\Delta \mathrm{L})=29.936-0.126 \mathrm{e}^{0.049 \Delta \mathrm{L}} \\
& q_{2}(\Delta \mathrm{L})=15.028+0.05 \ln (\Delta \mathrm{L})-0.119 \\
& q_{3}(\Delta \mathrm{L})=14.222+0.0136 \mathrm{e}^{0.044 \Delta \mathrm{L}}
\end{aligned}
$$

According to our numerical simulation data, $q_{4}=$ $14.0795 \mathrm{MPa}, q_{5}=14.2273 \mathrm{MPa}, q_{6}=29.3745 \mathrm{MPa}, \mathrm{L}_{1}$ $=42.857 \mathrm{~m}, \mathrm{~L}_{2}=116.327 \mathrm{~m}, \mathrm{~L}_{3}=85.714 \mathrm{~m}$, and $\mathrm{L}_{4}=55.102 \mathrm{~m}$.

It can be seen from Figure 1 that the Shanxi No.4 coal seam was $29.85 \mathrm{~m}$ from the No.3-5 coal seam, while the 

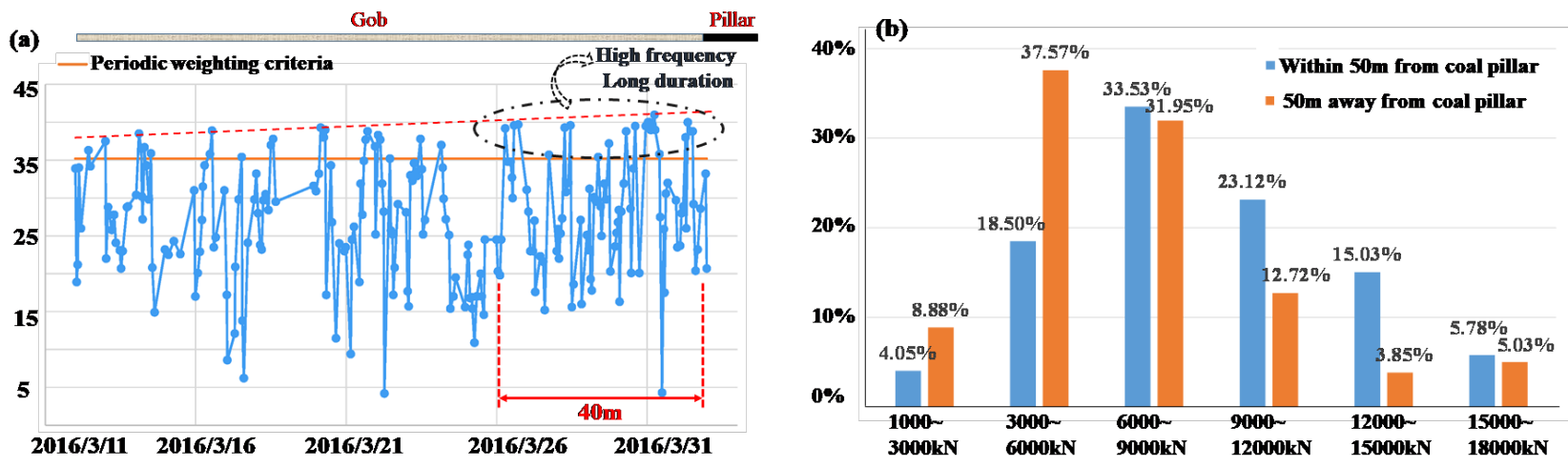

Figure 7: Characteristics of supports resistance: (a) Changes in the resistance of the supports; (b) Comparison of the working resistance.

8109 working face was mined for $3.5 \mathrm{~m}$ and caved for 12.72 $\mathrm{m}$ of the top coal. Therefore, the vertical distance of 8109 working face from the OCP was $y=42.57 \mathrm{~m}$. The horizontal distance of the working face from the OCP was 100$\Delta \mathrm{L}$ and the horizontal coordinate of the working face was $x=L_{1}+L_{2}+100-\Delta L=(259.184-\Delta L) \mathrm{m}$. The relationship between the locations of the coal seams was shown in Figure 6b. Substituting the above data into Eq. (2), the relationship between the vertical stress $\sigma_{y}$ in 8109 working face and $\Delta \mathrm{L}$ was gained, as shown in Figure $6 \mathrm{c}$.

As shown in Figure 6c, as the working face gradually mined near to the OCP, the vertical stress transmitted from the OCP to the working face increased. After the working face was within $45 \mathrm{~m}$ from the OCP, the vertical stress on the working face rose rapidly, indicated that the surrounding rock stress in the working face was strongly influenced by the OCP.

\section{Engineering Practice}

\subsection{Occurrence Characteristics of Strong Strata Behavior}

The 8109 working face was mined over a large thickness and therefore the overlying strata moved a large amount with a mining rate of $5 \mathrm{~m}$ per day. As the 8109 working face gradually mined to the position near to the OCP of the 8102 working face, strong ground pressure taken placed.

To study the effects of OCP on the ground pressure occurred in the working face, the supports resistance were monitored (Figure 7).

From Figure 7a we can see that as the 8109 working face gradually mined near to the OCP, the strong strata behavior occurred frequently, the values and densities of the curve peaks rose on the whole. In particular, when the working face was $40 \mathrm{~m}$ near to the OCP, high frequency and long duration of strong pressure occurred.

The working resistance of the supports were obtained within $50 \mathrm{~m}$ from the OCP of 8109 working face. The results were then compared with those obtained from 'normal' mining sections (non-influenced by the OCP) (Figure 7b).

From Figure 7b, we can see that the supports working resistance of the working face mainly ranged from 6000 to $15000 \mathrm{kN}$ within $50 \mathrm{~m}$ from the OCP. For these supports, the ranges 6000 to $9000 \mathrm{kN}$ and 9000 to $15000 \mathrm{kN}$ accounted for $33.53 \%$ and $38.15 \%$ of the total, respectively. However, for the normal mining section, the resistance of the supports essentially lies in the range 3000 to $12000 \mathrm{kN}$ and the range from 3000 to $9000 \mathrm{kN}$ accounted for the maximum proportion, reaching to $69.52 \%$, while the proportion of the resistance in the range 3000 to $6000 \mathrm{kN}$ was $37.57 \%$. Obviously, stress concentration in the OCP greatly affected the supports resistance in the working face. In addition, the surrounding rocks of the roadway were seriously deformed, which greatly limits normal production of the working face.

Moreover, in the process of 8109 working face mined near to the OCP. The support resistances were statistically analyzed. The statistical parameters from this analysis are shown in Table 1. As shown in Table 1, the resistance of the supports significantly increased as the working face mined near to the OCP. In the region of $0 \mathrm{~m}$ to $60 \mathrm{~m}$ from the OCP, the dynamic load factor of the supports ranges between 1.45 and 1.72 . The safety valve of the supports opened frequently, and the opening rate was as high as $43.1 \%$. In addition, supports crushed would occur occasionally, which seriously affected the safety of mining operations at the working face. 
Table 1: Characteristics of the support resistance

\begin{tabular}{lcccccc}
\hline $\begin{array}{c}\text { Relationship to the projection of } \\
\text { the OCP }\end{array}$ & $\begin{array}{c}100 \mathrm{~m} \\
\text { from the } \\
\text { OCP }\end{array}$ & $\begin{array}{c}80 \mathrm{~m} \text { from } \\
\text { the OCP }\end{array}$ & $\begin{array}{c}60 \mathrm{~m} \text { from } \\
\text { the OCP }\end{array}$ & $\begin{array}{c}40 \mathrm{~m} \text { from } \\
\text { the OCP }\end{array}$ & $\begin{array}{c}20 \mathrm{~m} \text { into } \\
\text { the OCP }\end{array}$ & $\begin{array}{c}0 \mathrm{~m} \text { into } \\
\text { the OCP }\end{array}$ \\
\hline $\begin{array}{c}\text { Average dynamic load factor of the } \\
\text { supports }\end{array}$ & 1.15 & 1.21 & 1.45 & 1.59 & 1.68 & 1.72 \\
\begin{tabular}{c} 
Safety valve opening rate $/ \%$ \\
\hline
\end{tabular} & 0 & 0 & 6.7 & 21.5 & 37.2 & 43.1 \\
\hline
\end{tabular}

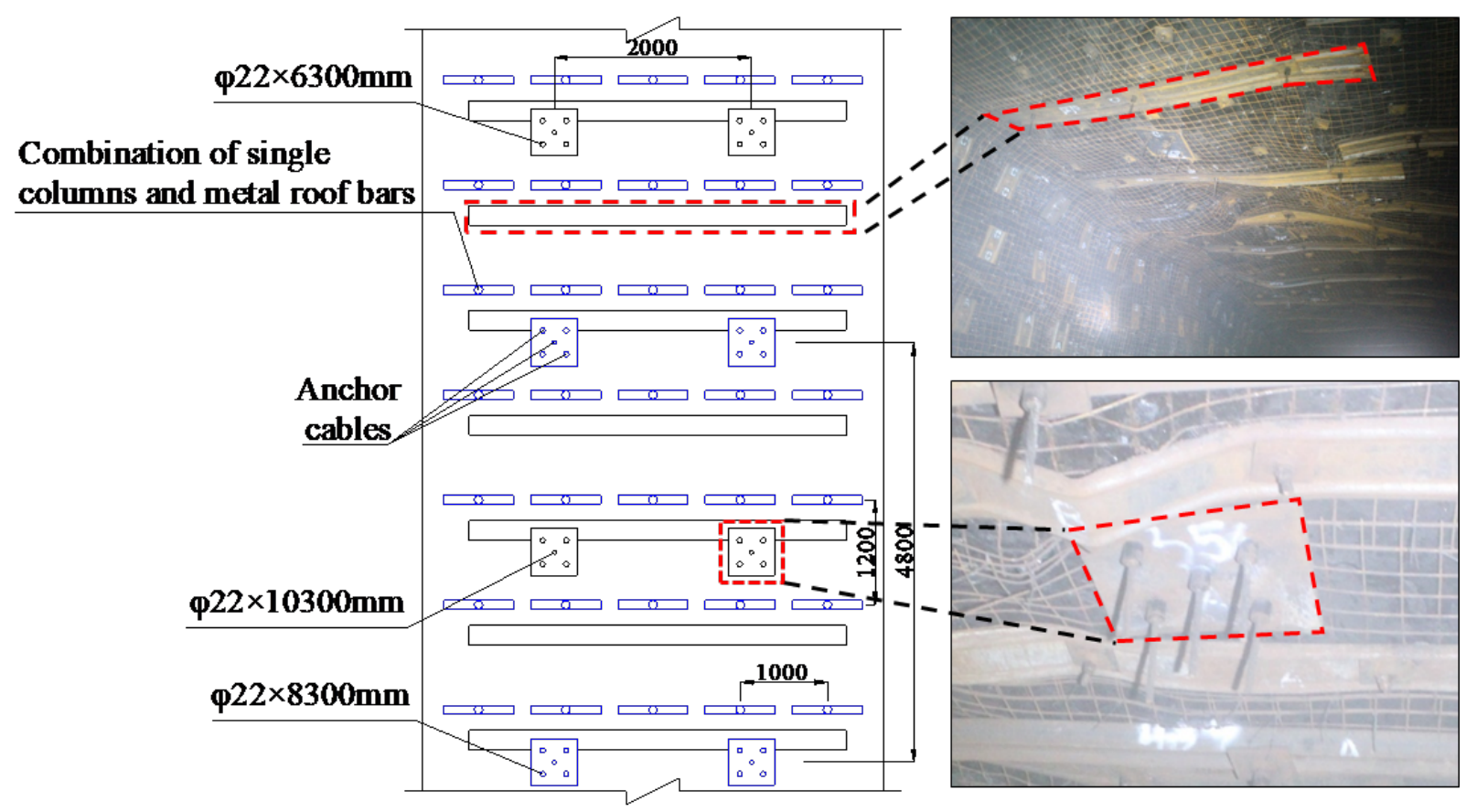

Figure 8: Roadway supports of the working face.

\subsection{Control of the Surrounding Rock in the Stope}

Influenced by the OCP, the occurrence of coal walls spalling and deformation of surrounding rocks in the roadways were severe. Through an appropriate adjustment of supports working condition, the rib spalling in the working face could been effectively controlled, and the control of the deformation in the roadways was significant. In the range $80 \mathrm{~m}$ from the OCP, another five rows of single columns were added in the supporting system of roadways. As shown in Figure 8, the supports marked in blue color represents the additional reinforcement. The column and row spacing of the single columns were $1.2 \mathrm{~m}$ and $1 \mathrm{~m}$, and the row spacing of the anchor cables were $2400 \times 2000 \mathrm{~mm}$. The anchoring force of cables were no less than $19 t$.

The OCP corresponded to the position of $960 \mathrm{~m}$ from the open-off cut of the 8109 working face. In order to measure the roadway deformation, six measurement points were set up at the position of $895,915,935,960,980$, and $1000 \mathrm{~m}$ along the roadway (Figure $9 \mathrm{a}$ ). In the range between where the working face was $132 \mathrm{~m}$ (March 9th) to $10 \mathrm{~m}$ (April 1st) away from the OCP, the height variation of the roadway at each point is shown in Figure 9(b). It can be seen from Figure 9(b) that the height variation at the $895 \mathrm{~m}$ point was maximal and the maximum change in the height were $0.66 \mathrm{~m}$. When the 8109 working face mined to this monitoring point, the height of the roadway were 2.95 $\mathrm{m}$, which meeting the needs of safe mining in the working face.

To demonstrate the effectiveness of the proposed solution, we compared the roadway deformation in an adjacent similar 8216 working face where an OCP was left at a vertical distance of $30 \mathrm{~m}$. The support parameters in the roadway were same as 8109 working face (as shown in Figure 8 without reinforced supports which marked in blue). The process of roadway deformation is shown in Figure 10. 

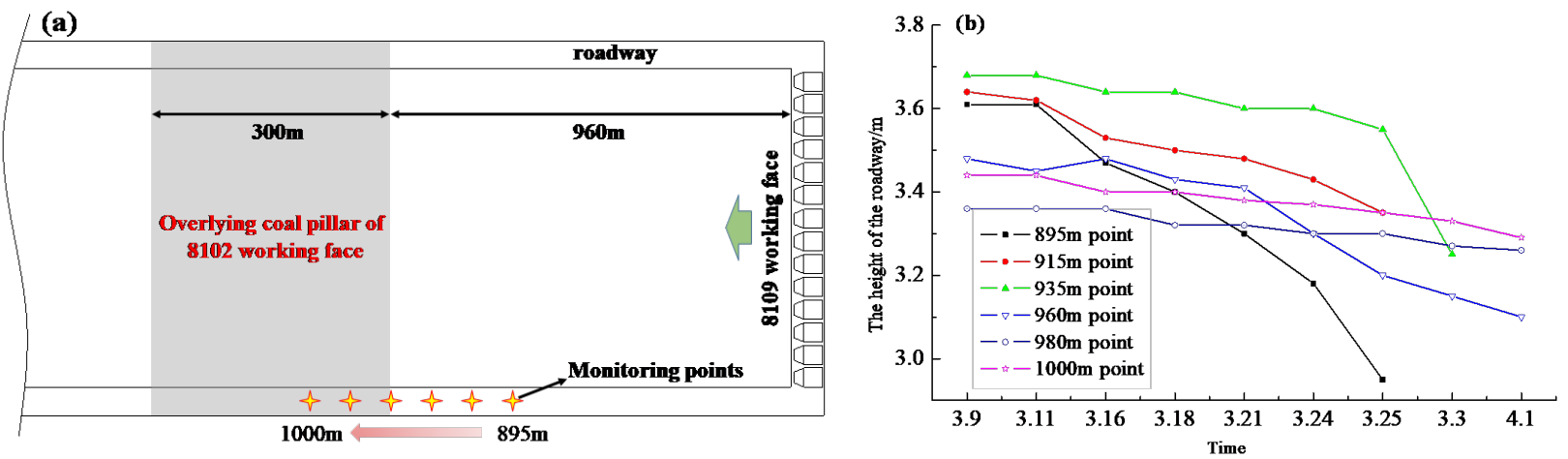

Figure 9: Layout of the monitoring points and the monitoring results: (a) Layout of the monitoring points; (b) Deformation of the height of the roadway.
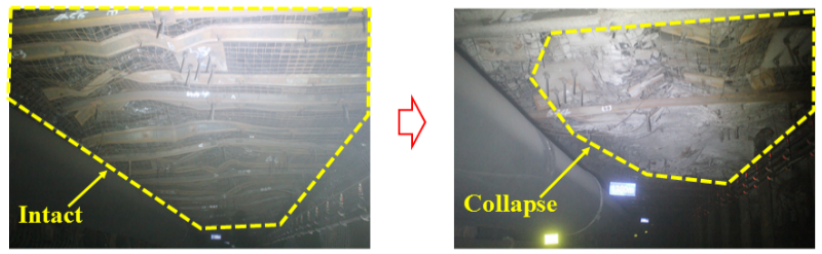

$80 \mathrm{~m}$ from the coal pillar

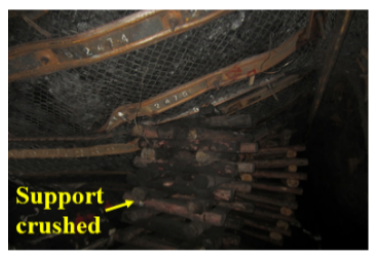

Om from the coal pillar

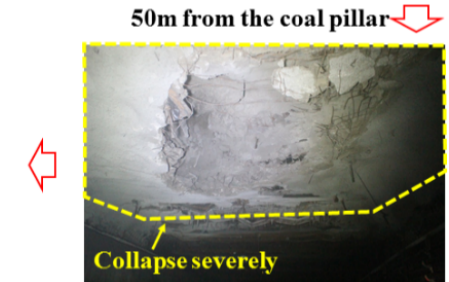

$20 \mathrm{~m}$ from the coal pillar

Figure 10: The process of roadway deformation.

As shown in Figure 10, when the working face was $80 \mathrm{~m}$ from the OCP, the roadway roof was intact. As the working face mined to the distance of $50 \mathrm{~m}$ to the OCP, roof collapsing occurred and when the working face was $20 \mathrm{~m}$ from the OCP, the roof collapsed severely. As influenced by the concentration stress of OCP, the wood support was crushed when the working face mined to the position of OCP. Compared to the roadway deformation of 8109 working face showed in Figure 8 and Figure 9, it was obvious that the support scheme in 8109 roadway was effective and could fully guarantee the safety mining of working face.

\section{Conclusions}

1. Numerical simulations indicated that the influence range of the concentrated stress in the OCP reached $90 \mathrm{~m}$, and the evolution characteristics of the stress in OCP with the advance of the working face was analyzed. Moreover, the characteristics of the stress and

displacement of the coal body in front of the working face were revealed.

2. Based on the numerical simulations, a functional expression for the change of OCP stress was obtained by data fitting. Theoretical calculations were further used to determine the change in the vertical stress transmitted from the OCP to the working face. Thus, the mechanism of strong strata behavior occurrence at the working face was revealed.

3. In situ monitoring demonstrated that within the region 40m away from the OCP, strong strata behavior frequently appeared in the working face and roadways. By applying supplementary anchor-cable supports, the surrounding rocks in the roadway could be successfully reinforced and controlled. The study on the mechanism of strong strata behavior in working face and the strengthen supporting scheme provide a theoretical basis for safe and efficiency coal seam mining. The research achievements in the manuscript provides technical supports and experiences for deep coal seam safe mining in similar conditions.

Acknowledgement: This research was funded by the State Key Research Development Program of China, grant number [2016YFC0600701], the State Key Research Development Program of China, grant number [2018YFC0604500], and China Postdoctoral Science Foundation, grant number [2019M651080].

\section{References}

[1] Yu, B. Study on strong pressure behavior mechanism and roof control of fully mechanized top coal caving in extra thickness seam in datong coal mine. Ph.D. diss., China University of Mining 
and Technology. Xuzhou, 2014.

[2] Yu B., Liu C.Y., Yang J.X., Liu J.R., Mechanism of strong pressure reveal under the influence of mining dual system of coal pillar in Datong mining area. J. China Coal Soc., 2014, 39, 40-46.

[3] Yu B., Zhu W.B., Gao R., Liu J.R., Strata structure and its effect mechanism of large space stope for fully-mechanized sublevel caving mining of extremely thick coal seam. J. China Coal Soc., 2016, 41, 571-580.

[4] Chen Y.L., Lu A.H., Mao X.B., Li M., Zhang L.Y., Nonlinear Dynamics Mechanism of Rock Burst Induced by the Instability of the Layer-Crack Plate Structure in the Coal Wall in Deep Coal Mining. Shock. Vib., 2017, 10, 1-12.

[5] Wang X.F., Wang Y., Zhang D.S., Wang H.Z., Zhang Y., Qin D.D., Zhang C.G., Characteristics of strata behavior during thick seam mining by fully-mechanized top coal caving in a loess-covered gullied region. Minerals., 2017, 7, 63.

[6] Basarir H., Oge I. F., Aydin O., Prediction of the stresses around main and tail gates during top coal caving by $3 \mathrm{~d}$ numerical analysis. Int. J. Rock Mech. Min. Sci., 2015, 76, 88-97.

[7] Zhu S.Y., Lu L.L., Wu Y., Comprehensive study on the deformation and failure characteristics of a mining-impacted deep doublelongwall working face floor. J. Geophys. Eng., 2017, 14, 641-653.

[8] Palchik V., Localization of mining-induced horizontal fractures along rock layer interfaces in overburden: field measurements and prediction. Environmental Geology., 2005, 48, 68-80.

[9] Zhang W., Yang Z., Zhang D.S., Wang X.F., Li P., Xu M.T., A novel comprehensive detection method for the dynamic characteristics of coalface overburden: a case study in China. Minerals., 2017, 7, 21.

[10] Gao R., Yu B., Xia H.C., Duan H.F., Reduction of Stress Acting on a Thick, Deep Coal Seam by Protective-Seam Mining. Energies., 2017, 10, 1209.

[11] Poulsen B.A., Coal pillar load calculation by pressure arch theory and near field extraction ratio. Int. J. Rock Mech. Min. Sci., 2010, 47, 1158-1165.

[12] Singh R., Singht T.N., Dhar B.B., Coal pillar loading in shallow mining conditions. Int. J. Rock Mech. Min. Sci., 1996, 33, 757768.

[13] Singh A.K., Singh R., Maiti J., Kumar R., Mandal P.K. Assessment of mining induced stress development over coal pillars during depillaring. Int. J. Rock Mech. Min. Sci., 2011, 48, 805-818.
[14] Singh R., Singh A.K., Maiti J., Mandal P.K., Singh R., Kumar R., An observational approach for assessment of dynamic loading during underground coal pillar extraction. Int. J. Rock Mech. Min. Sci., 2011, 48, 794-804.

[15] Jaiswal A., Shrivastva B.K., Numerical simulation of coal pillar strength. Int. J. Rock Mech. Min. Sci., 2009, 46, 779-788.

[16] Mohan G.M., Sheorey P.R., Kushwaha A., Numerical estimation of pillar strength in coal mines. Int. J. Rock Mech. Min. Sci., 2001, 38, 1185-1192.

[17] Wattimena R.K., Kramadibrata S., Sidi I.D., Azizi M.A., Developing coal pillar stability chart using logistic regression. Int. J. Rock Mech. Min. Sci., 2013, 58, 55-60.

[18] Ma T.H., Wang L., Suorineni F.T., Tang C.A., Numerical analysis on failure modes and mechanisms of mine pillars under shear loading. Shock. Vib., 2016, 1, 1-14.

[19] Wang S.L., Hao S.P., Chen Y., Bai J.B., Wang X.Y., Xu Y., Numerical investigation of coal pillar failure under simultaneous static and dynamic loading. Int. J. Rock Mech. Min. Sci., 2016, 84, 59-68.

[20] Ju J.F., Xu J.L., Zhu W.B., Liu K., Influence of cut-hole position on support crushing during mining out coal pillar at the side of upper goaf in close distance of shallow seams. Chin. J. Rock Mech. Eng., 2014, 33, 2018-2029.

[21] Ju J.F., Xu J.L., Zhu W.B., Longwall chock sudden closure incident below coal pillar of adjacent upper mined coal seam under shallow cover in the Shendong coal field. Int. J. Rock Mech. Min. Sci., 2015, 77, 192-201.

[22] Yang J.X., Liu C.Y., Yu B., Wu F.F., Calculation and analysis of stress in strata under gob pillars. J. Cent. South. Univ., 2015, 22, 1026-1036.

[23] Yang J.X., Liu C.Y., Yu B., Wu F.F., The effect of a multi-gob, piertype roof structure on coal pillar load-bearing capacity and stress distribution. B. Eng. Geol. Environ., 2015, 74, 1267-1273.

[24] Xia B.W., Jia J.L., Yu B., Zhang X., Li X.L., Coupling effects of coal pillars of thick coal seams in large-space stopes and hard stratum on mine pressure. International Journal of Mining Science and Technology., 2017, 27, 965-972. 